\title{
ANALISIS SENYAWA DALAM PARFUM ISI ULANG YANG BEREDAR DI KOTA BANDUNG DENGAN METODE KROMATOGRAFI GAS-SPEKTROMETRI MASSA (KG-SM)
}

\author{
Purwaniati*, Lisna Egisnawati, Emma Emawati \\ Analisis Farmasi dan Kimia Medisinal, Fakultas Farmasi, Universitas Bhakti Kencana \\ Jl. Soekarno-Hatta 754, Bandung, Indonesia \\ *Email : purwaniati@bku.ac.id
}

Received: 13/02/2021, Revised: 14/07/2021, Accepted: 19/07/2021, Published: 18/08/2021

\begin{abstract}
ABSTRAK
Pewangi atau parfum merupakan produk yang sangat banyak ditemukan dalam kehidupan seharihari. Produk parfum tidak dilengkapi dengan informasi yang cukup mengenai senyawa-senyawa yang digunakan didalamnya. Hal ini menyebabkan masyarakat tidak mengetahui potensi bahaya yang terkandung dalam parfum tersebut. Penelitian ini bertujuan menganalisis senyawa yang terdapat dalam parfum isi ulang tersebut. Analisis ini dilakukan dengan metode kromatografi gasspektrometri massa (KG-SM). Berdasarkan hasil analisis, parfum dengan aroma yang mirip menunjukkan mengandung senyawa-senyawa yang mirip pula. Dari lima sampel yang diuji, diketahui bahwa setiap sampel mengandung sekurang-kurangnya 24 senyawa. Dari semua senyawa tersebut, baru 5 senyawa yang telah ditentukan statusnya dalam Standard IFRA, yaitu limonene dan linalool yang statusnya spesificated, benzaldehyde dan citronellol yang statusnya restricted, dan lily aldehyde yang berstatus prohibited/restricted.
\end{abstract}

Kata kunci : analisis senyawa parfum, KGSM

\begin{abstract}
Fragrance or perfume is a product that is very much found in everyday life. Perfume products are not equipped with sufficient information about the compounds used in them. This causes people not to know the potential dangers contained in the perfume. This study aims to analyze the compounds contained in the refill perfume. This analysis was carried out by gas chromatographymass spectrometry (GC-MS) method. Based on the results of the analysis, perfumes with similar aromas indicate that they contain similar compounds. Of the five samples tested, it is known that each sample contains at least 24 compounds. Of all these compounds, only 5 compounds have their status determined in the IFRA Standard, namely limonene and linalool with a specific status, benzaldehyde and citronellol with a restricted status, and lily aldehyde with a prohibited/restricted status.
\end{abstract}

Keywords: perfume compounds analysis, GC-MS 


\section{PENDAHULUAN}

Parfum adalah produk yang sangat mudah ditemukan dalam kehidupan seharihari. Produk perbekalan kesehatan rumah tangga ini dapat hadir dalam berbagai bentuk. Produk yang dijual dengan label "parfum" maka sudah pasti mengandung parfum dan bahan tambahan lainnya. Parfum yang dijual dipasaran tidak dilengkapi dengan informasi tentang senyawa yang terdapat didalamnya. Informasi produk ini tidak disampaikan oleh produsen dengan dalih "rahasia dagang". Tidak adanya informasi mengenai senyawa yang terkandung dalam parfum sangat merugikan konsumen. Konsumen tidak mengetahui potensi bahaya yang mungkin ditimbulkannya.

Sejumlah studi membuktikan bahwa parfum adalah produk multisenyawa (Guć et al., 2021). Suatu produk parfum dapat mengandung puluhan hingga ratusan senyawa didalamnya. Kadarnya juga sangat beragam, dan kadang hadir dalam kadar yang sulit untuk dideteksi (sangat kecil). Kondisi tersebut bisa jadi alasan lain mengapa produsen tidak mencantumkan informasi senyawa dalam produknya. Jenis senyawa yang beragam dan kadar yang kecil, sangat menyulitkan proses analisisnya. Dan dari segi keamanan tentu saja belum diketahui tingkat keamanannya. Analisis senyawa ini diharapkan dapat memberikan informasi awal mengenai senyawa-senyawa yang terkandung dalam parfum, sehingga selanjutnya dapat dilakukan uji keamanan terhadap masing-masing senyawa tersebut.

IFRA (International Fragrance Association) suatu badan yang beranggotakan industri-industri parfum dunia telah mulai menetapkan regulasi berkenaan dengan parfum. IFRA melalui RIFM (Research Institute for Fragrance Materials) terus melakukan studi yang mengkaji keamanan material yang digunakan dalam parfum. IFRA mengklasifikasikan material parfum ke dalam 3 kelompok, yaitu: prohibited (dilarang), restricted (dibatasi), dan spesificated (boleh digunakan dengan spesifikasi tertentu) (IFRA, 2020).

Parfum terdiri atas campuran senyawa. Untuk menghasilkan aroma yang diinginkan dilakukan dengan melakukan pencampuran senyawa. Senyawa utama parfum umumnya berupa campuran minyak atsiri dan senyawa-senyawa penghasil aroma, fiksatif serta pelarut (Borgave \& Chaudhari, 2010). Untuk mendapatkan aroma yang dikehendaki, sejumlah bahan secara coba-coba ditambahkan. Senyawa penghasil aroma dapat dihasilkan dari bahanbahan alami maupun sintetik. Keduanya memiliki karakteristik yang sangat berbeda, 
Cinnamaldehyde dan coumarin merupakan contoh pewangi sintetik yang mulai disintesis sejak abad 19 (Ellena, 2008).

Ftalat adalah kelompok senyawa yang juga sering ditambahakan dalam parfum. Terutama ftalat berbobot molekul rendah seperti diethyl phthalate (DEP) dan diisobutyl phthalate (DiBP) yang berfungsi sebagai fiksatif (Zhang et al., 2020).

Data menunjukan bahwa campuran senyawa dalam suatu sediaan parfum sangat beragam jenis dan komposisinya. Diantaranya ada yang mencapai 100 senyawa (Tengku Ab Ghani et al., 2014). Aroma memang merupakan suatu sensasi yang bersifat personal yang sulit untuk dideskripsikan. Hingga saat ini belum ada parameter yang jelas yang dapat menjelaskan suatu aroma (Zarzo \& Stanton, 2006).

Regulasi penggunaan bahan-bahan dalam parfum di Indonesia belum tegas. Bahan-bahan yang berpotensi toksik pun sering digunakan dalam parfum. Hal ini tentu merugikan masyarakat (Siti Zulaikha et al., 2015).

Kromatografi gas yang dilengkapi dengan detektor spektrometri massa masih menjadi instrumen andalan untuk analisis senyawa parfum ini. Hal ini karena senyawasenyawa parfum memang merupakan senyawa yang mudah menguap yang mudah dianalisis dengan kromatografi gas. Detektor spektrometri massa yang kemudian mengenali senyawa-senyawa tersebut berdasarkan pola fragmentasi dan bobot molekulnya (Liu \& Zhu, 2019).

Pengembangan metode analisis senyawa-senyawa dalam parfum yang akurat dan presisi menjadi tantangan tersendiri. Matriks parfum menjadi sangat kompleks karena campuran material didalamnya (Brendel et al., 2020). Metode analisis lain seperti IMS (ion mobility spectrometry) dapat menjadi metode pilihan untuk analisis senyawa volatil pada kadar yang sangat kecil (Rodríguez-Maecker et al., 2017).

Penelitian ini bertujuan untuk mengetahui senyawa-senyawa dalam parfum isi ulang yang beredar di Kota Bandung. Analisis senyawa dilakukan terhadap parfum dengan aroma yang hampir sama, untuk mengetahui tren penggunaan bahan dalam parfum.

\section{METODE PENELITIAN}

Penelitian dilakukan dengan menganalisis senyawa-senyawa yang terdapat dalam sampel parfum dengan metode kromatografi gas-spektrometri massa. Sampel parfum adalah parfum isi ulang yang dijual di wilayah Kota Bandung. 
Senyawa parfum kemudian dikelompokkan menurut kategori IFRA.

\section{Alat dan Bahan}

Alat-alat yang digunakan dalam penelitian ini meliputi: seperangkat kromatografi gas-spektrometri massa (KGSM) Shimadzu GCMS-QP 2010 SE. Fase diam yang digunakan yaitu kolom kapiler Shimadzu SH-Rxi-5Sil MS. Selain itu digunakan pula mikropipet 10-100 $\mu$, labu ukur 10 dan $100 \mathrm{ml}$.

Bahan yang digunakan yaitu: nheksana pro analisis, dan sampel parfum. Sampel parfum dibeli secara acak di toko parfum yang tersebar di Kota Bandung.

\section{Jalannya Penelitian}

Penelitian ini dilakukan dalam 4 langkah utama:

\section{Sampling}

Sampling produk parfum isi ulang dilakukan dengan membeli secara acak bibit parfum yang dijual di toko parfum isi ulang di wilayah Kota Bandung. Dalam penelitian ini diuji 5 sampel parfum isi ulang yang masing-masing diberi kode $\mathrm{A}, \mathrm{B}, \mathrm{C}, \mathrm{D}, \mathrm{E}$ (kelima sampel ini memiliki aroma yang mirip).

\section{Preparasi sampel}

Masing-masing sampel parfum diencerkan 100 kali. Pengenceran bertujuan agar konsentrasi masing-masing senyawa yang akan dianalisis dengan KG-SM tidak terlalu pekat. Pengenceran dilakukan dengan memipet $100 \mu 1$ sampel parfum kemudian dimasukan ke dalam labu ukur $10 \mathrm{ml}$ dan ditambahkan n-heksana hingga tanda batas. Sampel yang telah diencerkan kemudian dimasukkan ke dalam vial kromatografi gas dengan volume sekitar $1 \mathrm{ml}$. masing-masing vial dilabel sesuai dengan kode sampel.

\section{Pengkondisian KG-SM}

Sebelum digunakan untuk analisis sampel, alat KG-SM terlebih dahulu harus dikondisikan hingga dapat digunakan untuk analisis. Gas pembawa yang digunakan yaitu helium, dengan suhu injektor $300^{\circ} \mathrm{C}$, dan suhu oven pada kolom $40^{\circ} \mathrm{C}$. Detail kondisi KG-SM dapat dilihat pada Tabel 1.

4. Analisis sampel dengan KG-SM

Sampel yang telah disiapkan dalam masing-masing vial kemudian dianalisis dengan KG-SM.

\section{Analisis Data}

Setiap kromatogram yang dihasilkan kemudian dianalisis lebih lanjut dengan menggunakan data fragmentasi massanya $(\mathrm{m} / \mathrm{z})$. Identitas kimiawi suatu senyawa ditentukan berdasarkan nilai similarity index (SI) fragmentasi massa (spektra massa) senyawa dengan library. Dalam hal ini digunakan 2 library, yaitu: NIST (National 
Institute of Standards and Technology) dan Wiley.

Tabel 1. Kondisi KG-SM dalam percobaan

\begin{tabular}{|c|c|}
\hline Uraian & Spesifikasi \\
\hline \multirow[t]{3}{*}{ Merk } & Shimadzu \\
\hline & GCMS-QP \\
\hline & $2010 \mathrm{SE}$ \\
\hline \multirow[t]{2}{*}{ Fase diam } & Shimadzu SH- \\
\hline & Rxi-5Sil MS \\
\hline Gas pembawa & Helium UHP \\
\hline \multirow[t]{2}{*}{ Detector } & Spektrometri \\
\hline & massa \\
\hline \multicolumn{2}{|l|}{ Pengaturan suhu: } \\
\hline Injektor & $300^{\circ} \mathrm{C}$ \\
\hline Oven & $40^{\circ} \mathrm{C}$ \\
\hline Detektor & $250^{\circ} \mathrm{C}$ \\
\hline Awal & $60^{\circ} \mathrm{C}$ \\
\hline Laju kenaikan suhu & $10^{\circ} \mathrm{C} / \mathrm{menit}$ \\
\hline Suhu akhir & $300^{\circ} \mathrm{C}$ \\
\hline
\end{tabular}

\section{HASIL DAN PEMBAHASAN}

Kromatogram dari masing-masing sampel parfum menunjukkan adanya lebih dari 20 puncak pada tiap kromatogram. Jumlah puncak mengindikasikan jumlah senyawa dalam tiap sampel, Sampel A, B,
C, D dan E memberikan aroma yang hampir sama, hasil analisis terhadap kromatogramnya juga menunjukan adanya kemiripan senyawa.

Kromatogram sampel A, B, C, D dan E dapat dilihat pada Gambar 1. Sedangkan senyawanya dapat dilihat pada Tabel 2 .

Dari data pada Tabel 2 dapat diketahui bahwa, suatu produk parfum dengan aroma yang hampir sama cenderung memiliki kandungan senyawa yang hampir sama pula. Dari 5 sampel yang dikaji, jumlah senyawa yang terdeteksi hampir sama, yaitu berkisar antara 24 hingga 26 senyawa. Sembilan senyawa diantaranya terdeteksi pada semua sampel yang dapat dilihat pada Tabel 3. Total senyawa yang teridentifikasi dari semua sampel adalah 46. Berdasarkan Amandemen ke 50 Standard IFRA, baru 5 senyawa diantaranya yang telah jelas status keamanannya, yaitu linalool dan limonene yang berstatus spesificated, benzaldehyde dan citronellol yang berstatus restricted, dan lily aldehyde yang berstatus ganda, restricted dan prohibited (IFRA, 2021).

Tabel 2. Senyawa yang terkandung dalam sampel A, B, C, D dan E

\begin{tabular}{|c|c|c|c|c|c|c|c|}
\hline \multirow{2}{*}{ Nama Senyawa } & \multirow{2}{*}{$\begin{array}{c}\text { Rt } \\
\text { (menit) }\end{array}$} & \multicolumn{5}{|c|}{ \% Area Sampel } & \multirow{2}{*}{$\begin{array}{c}\text { Katagori } \\
\text { IFRA }\end{array}$} \\
\hline & & $\mathbf{A}$ & $\mathbf{B}$ & $\mathrm{C}$ & D & $\mathbf{E}$ & \\
\hline $\begin{array}{c}\text { Acetonotril (CAS) methyl } \\
\text { cyanide }\end{array}$ & 3,03 & 5,64 & - & 4,6 & 4,98 & - & $X$ \\
\hline
\end{tabular}




\begin{tabular}{|c|c|c|c|c|c|c|c|}
\hline Ethylbenzene & 5,45 & 1,39 & 0,86 & 18 & 1,42 & 1,3 & \\
\hline $\begin{array}{l}\text { Bicyclo[3.1.0] hexane-6,6- } \\
\text { dicarbonitrile }(C A S)\end{array}$ & 5,58 & 1,87 & - & - & - & - & $\mathrm{X}$ \\
\hline $\begin{array}{c}\text { 1-Propene,3,3'-[1,2- } \\
\text { ethanediylbis(oxy)]bis- } \\
\text { (CAS) }\end{array}$ & 6,52 & - & 0,65 & - & 0,94 & 0,91 & $\mathrm{X}$ \\
\hline $\begin{array}{c}\text { 2-Propenyl } \\
\text { Difluorocyclopropyl)methyl } \\
\text { Ether }\end{array}$ & 6,52 & 1,03 & - & - & - & - & $\mathrm{X}$ \\
\hline $\begin{array}{c}2,3,3,4,4- \\
\text { Pentafluorocyclobut-1-enyl } \\
\text { allyl ether }\end{array}$ & 6,52 & - & - & 0,86 & - & - & $\mathrm{X}$ \\
\hline $\begin{array}{c}\text { 2,4-bis }(n-H e x y l)-1,3- \\
\text { dithiethane-1,1,3,3- } \\
\text { tetraoxide }\end{array}$ & 6,91 & - & - & - & - & 0,98 & $\mathrm{X}$ \\
\hline Beta-myrcene & 7.06 & 1,75 & 0,61 & - & - & - & $\mathrm{X}$ \\
\hline Beta pinene & 7,15 & - & 3,62 & 2,91 & 2,28 & 2,71 & $\mathrm{X}$ \\
\hline Butyronitrile & 7,24 & - & 0,59 & - & - & - & $\mathrm{X}$ \\
\hline $\begin{array}{c}\text { Ethanone, 1-(4- } \\
\text { nitrophenyl)- (CAS) }\end{array}$ & 7,51 & - & 0,78 & - & - & - & $\mathrm{X}$ \\
\hline Borane carboxyl & 7,63 & $\begin{array}{c}19,8 \\
1\end{array}$ & - & - & - & - & $\mathrm{X}$ \\
\hline 1-propanol & 7,71 & -- & - & - & - & - & $\mathrm{X}$ \\
\hline $\begin{array}{l}\text { 2-propanol, } 1,1^{\prime} \text {-oxybis- } \\
(C A S) \text { atau dipropylene } \\
\text { glycol }\end{array}$ & 7,72 & $\begin{array}{c}18,7 \\
3\end{array}$ & $\begin{array}{c}12,6 \\
3\end{array}$ & $\begin{array}{c}14,6 \\
4\end{array}$ & $\begin{array}{c}10,0 \\
4\end{array}$ & $\begin{array}{c}16,1 \\
9\end{array}$ & $\mathrm{X}$ \\
\hline Limonene & 7,72 & - & - & $\begin{array}{c}15,1 \\
1\end{array}$ & $\begin{array}{c}14,3 \\
0\end{array}$ & 8,39 & $\mathrm{~S}$ \\
\hline $\begin{array}{l}\text { Cyclohexene, 1-methyl-4-(1- } \\
\text { methylethenyl)-(CAS) 1-p- } \\
\text { mentha-diene }\end{array}$ & 7,82 & 6,18 & $\begin{array}{c}15,5 \\
1\end{array}$ & $\begin{array}{c}10,5 \\
8\end{array}$ & - & - & $\mathrm{X}$ \\
\hline e-dipropylen glycol & 7,94 & $\begin{array}{c}11,1 \\
5\end{array}$ & 7 & 7,81 & 9,34 & - & $X$ \\
\hline $\begin{array}{c}\text { Isobutyl isopentanoic acid } \\
\text { ester }\end{array}$ & 8,07 & - & - & - & 0,53 & - & $\mathrm{X}$ \\
\hline Oxazoline & 8,07 & - & 0,78 & - & - & 0.83 & $\mathrm{X}$ \\
\hline $\begin{array}{cl}\text { 1-Propene, } & 3 \text {-bromo- } \\
(C A S) & \text { Allyl }\end{array}$ & 8,15 & - & - & - & - & 0,91 & $\mathrm{X}$ \\
\hline Gamma-terpinene & 8,17 & 0,86 & 1,99 & 1,14 & 1,45 & - & $\mathrm{X}$ \\
\hline $\begin{array}{c}\text { Pentanenitrile }(C A S) \text { Butyl } \\
\text { cyanide }\end{array}$ & 8,37 & - & 0,62 & - & - & - & $\mathrm{X}$ \\
\hline
\end{tabular}


Pharmacoscript Volume 4 No. 2 Agustus 2021

$\begin{array}{cccccccc}\text { l-linalool } & 8,64 & 3,15 & - & 4,66 & - & 4.35 & \mathrm{~S} \\ \text { Alpha-terpinolene } & 8,64 & - & 5,87 & - & 4,45 & & \mathrm{X} \\ \text { Linalool } & 9,75 & 3,42 & 5,12 & 4,86 & 4,31 & 4,76 & \mathrm{~S} \\ \text { 3-Octanyl acetat } & 9,83 & - & - & - & - & 1,67 & \mathrm{X}\end{array}$

1,2-Cyclohexanediol,

lmethyl-, trans- $(C A S)$ trans-

1-Methyl-1,2-

9,83

cyclohexanediol

1-Butanol, 2,3-dimethylacetate

$10,04 \quad 2,25 \quad-\quad-\quad-\quad-\quad 2,28 \quad X$

Hexanoic acid, 3-oxoethyl ester

$10,05 \quad-\quad-2,67 \quad-\quad-\quad-\quad X$

Citronelol

Citronelyl acetat

$\begin{array}{lllllll}10,24 & 1,01 & 1,77 & 1 & 1,59 & 0,87 & \mathrm{R}\end{array}$

$\begin{array}{llllllll}10,24 & - & - & - & - & 1,35 & \mathrm{X}\end{array}$

1,6-Octadien-3-ol, 3,7dimethyl-, 2- aminobenzoate

$10,41 \quad 1,92 \quad 3,67 \quad 2,54 \quad 2,23 \quad 2,55 \quad X$

Octanal, 7-hydroxy-3,7dimethyl- (CAS)

Hydroxycitronellal

$\begin{array}{lllllll}10,88 & 1,07 & 0,99 & 0,88 & 4,34 & 0.87 & \mathrm{X}\end{array}$

Cyclohexanol, 2-(1,1-

$\begin{array}{llllllll}\text { dimethylethyl)-(CAS) 2-tert- } & 10,99 & 1,33 & 1,93 & 1,81 & 1,79 & 1,7 & \mathrm{X}\end{array}$ Butylcyclohexanol

5-Hepten-1-ol, 2,6-dimethyl(CAS)

$11,22 \quad-\quad-\quad-\quad-\quad 0,38 \quad-\quad x \quad X$

Lily aldehide

$13,08 \quad 4,84 \quad 4,95 \quad 5,25 \quad 5,17 \quad 5,12 \quad \mathrm{R} / \mathrm{P}$

1,2-Benzenedicarboxylic

acid, diethyl ester (CAS)

Ethyl phthalate

Dihydro methyl jasmonate

Octanal, 2-

(phenylmethylene)- (CAS)

Hexyl cinnamic aldehyde

$\begin{array}{llllll}13,45 & 2,33 & - & 2,53 & - & 2,78\end{array}$

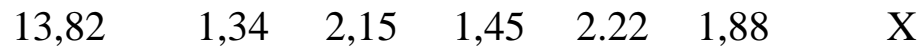

$\begin{array}{lllllll}14,39 & 3,8 & 4,6 & -- & - & 4,69 & X\end{array}$

$\begin{array}{llllllllll}\text { Alpha hexilcinamic aldehide } & 14,39 & - & - & 4,16 & - & - & & \mathrm{X}\end{array}$

$\begin{array}{llllllll}\text { Isopropyl myristate } & 14,66 & - & 2,42 & - & 2,24 & - & \mathrm{X}\end{array}$

Naphthalene, 6,7-diethyl-

$\begin{array}{llllllll}\text { 1,2,3,4-tetrahydro-1,1,4,4- } & 14,73 \quad & - & - & - & 0,45 & - & \mathrm{X}\end{array}$

tetramethylm(CAS) 
Purwaniati et al.;Analisis Senyawa Dalam Parfum.....Pharmacoscript Volume 4 No. 2, Agustus 2021

Oxacycloheptadec-8-en-2one (CAS) Ambrettolide

Hexamethyl-pyranoindane

$\begin{array}{ccccccc}14,86 & 1,25 & - & 1,41 & - & - & X \\ 14,91 & 2,83 & - & 3,1 & 2,72 & 3.31 & X\end{array}$

1,3,4,6,7,8-hexahydro-

$4,6,6,7,8,8$

examethylcyclopenya $(G)-2-$

14.94

$-\quad 3,18$

$\mathrm{X}$

benzopyran Atau galaxolide

\begin{tabular}{cccccccc} 
Benzaldehyde & 15,05 & 1,01 & 1,51 & 1,55 & 1,36 & 1,4 & $\mathrm{R}$ \\
Cyclodecanone & 15,66 & 1,62 & - & - & - & - & $\mathrm{X}$ \\
decanoic acid $($ CAS $)$ & 15,66 & - & 2,86 & 1,79 & 2,66 & 2,82 & $\mathrm{X}$ \\
\hline \multirow{2}{*}{ Total \%Area } & & $\mathbf{1 0 1}$ & $\mathbf{8 8 , 2}$ & $\mathbf{1 1 0}$, & $\mathbf{8 2 , 7}$ & $\mathbf{7 6 , 0}$ & \\
Total Senyawa & & $\mathbf{6 6}$ & $\mathbf{4}$ & $\mathbf{5 9}$ & $\mathbf{3}$ & $\mathbf{6}$ & \\
\hline
\end{tabular}

Keterangan: $\mathrm{R}=$ restricted, $\mathrm{S}=$ specificated, $\mathrm{X}=$ blm ditentukan statusnya

Tabel 3. Senyawa yang terdapat pada semua sampel parfum

\begin{tabular}{|c|c|}
\hline No & Nama Senyawa \\
\hline 1 & Ethylbenzene \\
\hline 2 & 2-propanol, 1,1'-oxybis- $\quad(C A S)$ atau dipropylene glycol \\
\hline 3 & Linalool \\
\hline 4 & Citronellol \\
\hline 5 & 1,6-Octadien-3-ol, 3,7-dimethyl-, 2-aminobenzoate \\
\hline 6 & Octanal, 7-hydroxy-3,7-dimethyl-(CAS) Hydroxycitronellal \\
\hline 7 & Cyclohexanol, 2-(1,1- dimethylethyl)-(CAS) 2-tert-Butylcyclohexanol \\
\hline 8 & Lily aldehide \\
\hline 9 & Dihydro methyl jasmonate \\
\hline
\end{tabular}

Limonene dan linalool dinyatakan spesificated, artinya kedua senyawa tersebut boleh digunakan dalam parfum namun dengan syarat tertentu, Limonene dinyatakan specificated melalui amandemen ke 29 Standards IFRA tahun 1995. Limonene boleh digunakan dalam parfum hanya jika produk oksidasinya dapat terkontrol oleh penambahan antioksidan (IFRA, 1995). Linalool boleh digunakan dengan syarat kadar peroksidanya tidak lebih dari 20 $\mathrm{mmol} / \mathrm{L}$. Linalool yang digunakan dapat berupa l-linalool, $d$-linalool maupun $d l$ linalool. Status spesificated linalool ini telah ditetapkan sejak tahun 2004 melalui amandemen standard IFRA ke 38 (IFRA, 2004).

Benzaldehyde dinyatakan boleh digunakan dalam parfum dalam batas tertentu melalui amandemen standard IFRA 
ke 47 tahun 2013. Kadar yang diperbolehkan pada produk akhir berkisar antara 0,02\% hingga $3 \%$ tergantung kategori produk (IFRA, 2013). Citronellol ditetapkan statusnya pada amandemen ke 42 Standard IFRA tahun 2007. Kadar yang diperbolehkan berkisar antara 0,8-13,3\% (IFRA, 2007). Studi lebih lanjut terhadap kadar benzaldehyde dan citronellol dalam parfum ini tentu harus dilakukan untuk memastikan bahwa kadarnya tidak melebihi batas yang telah ditentukan.

$$
\text { Lily aldehyde dilarang }
$$
penggunaannya untuk produk lipstik dan perawatan area mulut lainnya. Namun masih diperbolehkan sebagai parfum untuk produkproduk kosmetik lainnya (IFRA, 2020).
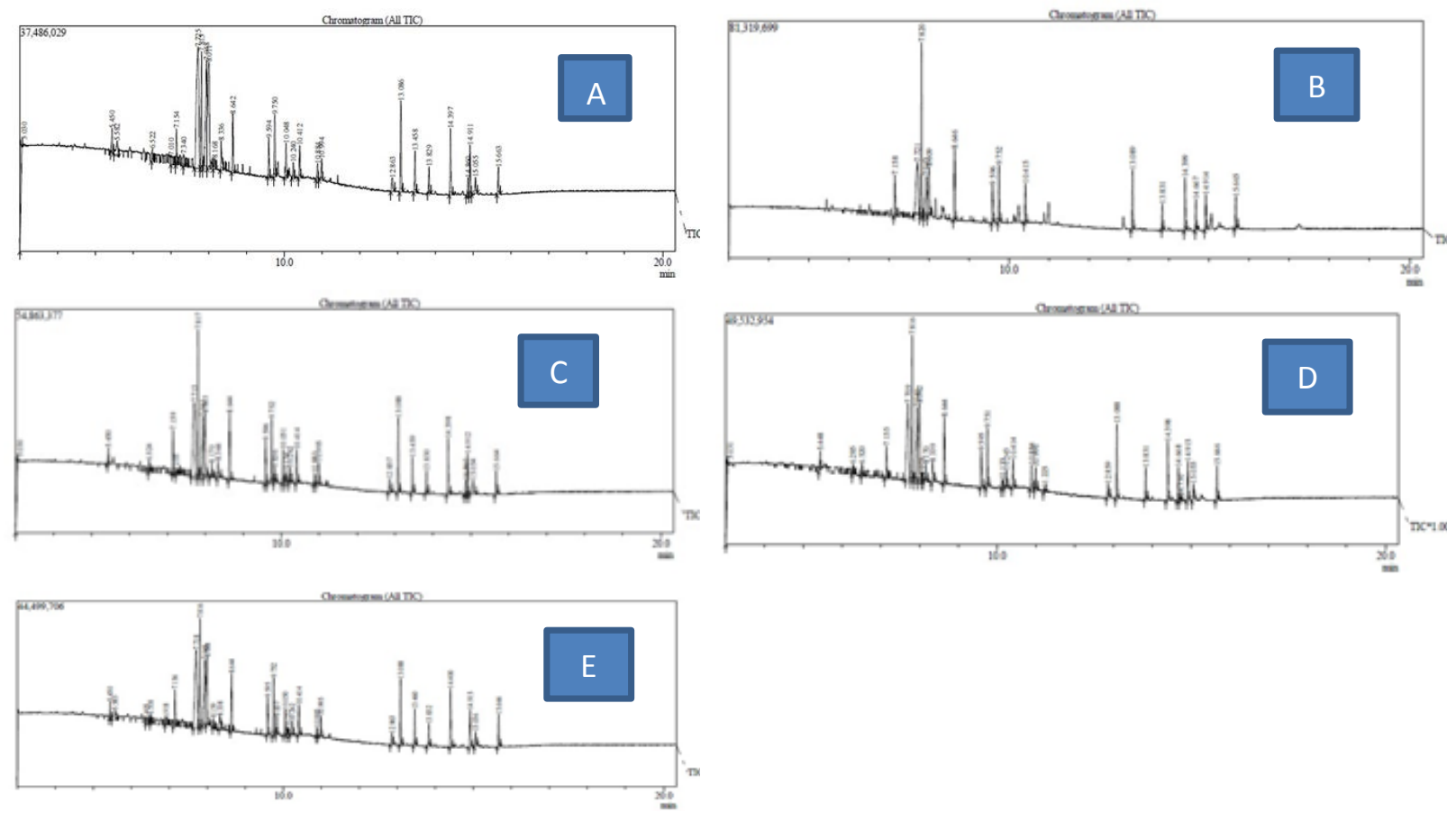

Gambar 1. Kromatogram sampel A, B, C, D dan E
Berdasarkan data dalam Tabel 1, maka dapat diketahui bahwa masih banyak senyawa yang terkandung dalam parfum yang belum jelas status keamanannya. Maka penelitian ini harus dilanjutkan dengan menguji keamanan sejumlah senyawa yang belum ditetapkan status keamanannya tersebut, Penelitian untuk mengkaji keamanan senyawa-senyawa tersebut terus dilakukan. Methyl dihydrojasmonate misalnya, dinyatakan aman dalam sebuah studi yang dilakukan oleh Api dkk (Api et al., 2020). Studi keamanan terhadap diethyl phthalate juga dilakukan oleh Api dkk. Penelitian tersebut menyatakan bahwa senyawa ini relatif aman digunakan dalam parfum (Api, 2001). 


\section{KESIMPULAN}

Berdasarkan data analisis senyawa terhadap parfum ini maka dapat disimpulkan bahwa parfum merupakan produk yang mengandung berbagai campuran senyawa. Pada sampel A, B, dan C terdapat 26 senyawa, sampel D 24 senyawa dan sampel E 25 senyawa. 9 Senyawa terdapat pada semua sampel, Terdapat lima senyawa yang telah ditentukan status keamananya menurut Standard IFRA. Lima senyawa tersebut adalah limonene dan linalool yang berstatus spesificated, benzaldehyde dan citronellol yang berstatus restricted, serta lily aldehyde yang berstatus ganda restricted dan prohibited.

\section{DAFTAR PUSTAKA}

Api, A. M. (2001). Toxicological profile of diethyl phthalate: A vehicle for fragrance and cosmetic ingredients. Food and Chemical Toxicology, 39(2), 97-108.

https://doi.org/10.1016/S0278-

6915(00)00124-1

Api, A. M., Belsito, D., Biserta, S., Botelho, D., Bruze, M., Burton, G. A., Buschmann, J., Cancellieri, M. A., Dagli, M. L., Date, M., Dekant, W., Deodhar, C., Fryer, A. D., Gadhia, S., Jones, L., Joshi, K., Lapczynski, A.,
Lavelle, M., Liebler, D. C., ... Tsang, S. (2020). RIFM fragrance ingredient safety assessment, cinnamyl alcohol, CAS Registry Number 104-54-1. In Food and Chemical Toxicology. https://doi.org/10.1016/j.fct.2020.1113 37

Borgave, S., \& Chaudhari, J. S. (2010). Adolescents' preferences and attitudes towards perfumes in India. Journal of Policy and Organisational Management, 1(2), 1-8.

Brendel, R., Schwolow, S., Rohn, S., \& Weller, P. (2020). Comparison of PLSR, MCR-ALS and Kernel-PLSR for the quantification of allergenic fragrance compounds in complex cosmetic products based on nonlinear 2D GC-IMS data. Chemometrics and Intelligent Laboratory Systems, 205(May), 104128. https://doi.org/10.1016/j.chemolab.20 20.104128

Guć, M., Cegłowski, M., Pawlaczyk, M., Kurczewska, J., Reszke, E., \& Schroeder, G. (2021). Application of FAPA mass spectrometry for analysis of fragrance ingredients used in cosmetics. Measurement: Journal of the International Measurement Confederation, 168(May 2020). 
https://doi.org/10.1016/j.measurement. 2020.108326

IFRA. (1995). Amendment 29 IFRA STANDARD Limonene formula: Structure: History: FRAGRANCE INGREDIENT IFRA STANDARD. 1995(Amendment 29), 1-3.

IFRA. (2004). IFRA Standards - 38th Amandement. 1-2.

IFRA. (2007). IFRA Standards - 42th Amandement. Annex 1 to the IFRA Standards.

IFRA. (2013). IFRA Standards - 47th Amandement. IFRA, 47th Amendment, 2 , https://ifrafragrance.org/standards/IFR A_STD48_0149.pdf

IFRA. (2020). Guidance for the Use of IFRA Standards. 45-46. https://ifrafragrance.org/docs/defaultsource/ifra-code-of-practice-andstandards/49th-amendment/ifra-49thamendment-(att-01)---guidance-forthe-use-of-ifrastandardsa7006c445f36499bbb0eb141 e8c0d4be.pdf?sfvrsn=7fb244c8_2

IFRA. (2021). IFRA Standards 50th Amandement - Index of IFRA Standards. 32(0). http://www.ifraorg.org/Upload/Downl oadButtonDocuments/4d5e6594-9c1b-
4b10-b650-3abdc0e0134a/Index of IFRA Standards 48th Amendment.pdf Liu, S., \& Zhu, Y. (2019). Determination of 27 fragrances in cosmetics and perfume raw materials by gas chromatography-mass spectrometry. Se $P u=$ Chinese Journal of Chromatography. https://doi.org/10.3724/SP.J.1123.201 9.01045

Rodríguez-Maecker, R., Vyhmeister, E., Meisen, S., Rosales Martinez, A., Kuklya, A., \& Telgheder, U. (2017). Identification of terpenes and essential oils by means of static headspace gas chromatography-ion mobility spectrometry. Analytical and Bioanalytical Chemistry, 409(28), 6595-6603.

https://doi.org/10.1007/s00216-0170613-2

Siti Zulaikha, R., Sharifah Norkhadijah, S. I., \& Praveena, S. M. (2015). Hazardous Ingredients in Cosmetics and Personal Care Products and Health Concern : A Review. Public Health Research. https://doi.org/10.5923/j.phr.20150501 .02

Tengku Ab Ghani, T. F., Maarof, H., \& Hassan, M. N. (2014). Classification of perfume products using gas 
chromatography-mass spectrometry and pattern recognition. Malaysian

Journal of Fundamental and Applied

Sciences.

https://doi.org/10.11113/mjfas.v10n3.

266

Zarzo, M., \& Stanton, D. T. (2006). Identification of latent variables in a semantic odor profile database using principal component analysis. Chemical Senses. https://doi.org/10.1093/chemse/bj1013 Zhang, Q., Sun, Y., Zhang, Q., Hou, J., Wang, P., Kong, X., \& Sundell, J. (2020). Phthalate exposure in Chinese homes and its association with household consumer products. Science of the Total Environment, 719, 136965. https://doi.org/10.1016/j.scitotenv.202 0.136965 